다잉

WVIERSIDAD DEGLADLLAIAPAA

\title{
EDITORIAL
}

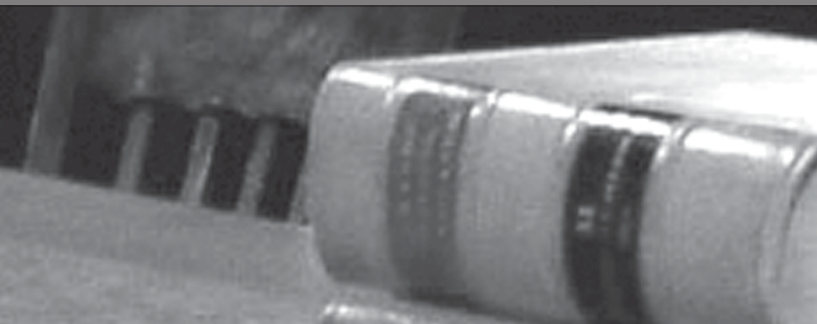




\section{El Derecho Humano a la Educación}

La educación es un derecho fundamental, esencial para poder ejercitar todos los demás derechos que establece nuestra constitución; con la educación se abre la posibilidad de consolidar la democracia y el pleno ejercicio de los derechos humanos ya que se promueve la libertad, la autonomía personal y consecuentemente se aportan beneficios para el desarrollo social.

Los principios que regulan el Derecho a la educación son: El principio de no discriminación, el principio de igualdad de oportunidades y el principio de solidaridad.

El principio de no discriminación consiste en que todos los seres humanos deben tener acceso a la educación, tanto de derecho como de hecho. La discriminación abarca toda distinción, exclusión, limitación o preferencia, fundada en la raza, el color, el sexo, el idioma, la religión, las opiniones políticas o de cualquier otra índole, el origen nacional o social, la posición económica o el nacimiento, que tenga por finalidad o por efecto destruir o alterar la igualdad de trato en la esfera de la enseñanza.

El principio de igualdad de oportunidades tiene que ver con procurar la igualdad de posibilidades y de trato para todas las personas en la esfera educativa. Se establece en el preámbulo de la Constitución de la UNESCO: "El acceso a los estudios superiores será igual para todos, en función de los méritos respectivos".

El principio de solidaridad se refiere a la solidaridad intelectual y moral de la humanidad, consagrado en la Constitución de la UNESCO: "ningún país que se comprometa seriamente con la educación para todos se verá frustrado por falta de recursos en su empeño por lograr esa meta".

La educación que recibe cada persona debe ser de calidad, sin discriminación ni exclusión, así en el año 2008 la UNESCO en la $48^{\circ}$ Conferencia Internacional, trabajó hacia una transformación en las políticas públicas en educación en donde se modifiquen las estructuras y los sistemas educativos para lograr no solo integrar a ciertos estudiantes a la enseñanza convencional, sino transformar los entornos de aprendizaje con el fin de responder a la diversidad de los estudiantes, esto es, permitir que los maestros y alumnos se sientan cómodos ante la diversidad y la perciban no como un problema, sino como un desafio y una oportunidad para enriquecer las formas de enseñar y aprender; con lo cual se contribuye a alcanzar la equidad y justicia en el derecho humano a la educación". 
La inclusión social pasa necesariamente, por una mayor inclusión en la educación, es decir, por el desarrollo de escuelas o contextos educativos que acojan a todas las personas de la sociedad, independientemente de su procedencia social, cultural o características individuales, logrando integrar la diversidad del alumnado favoreciendo así la cohesión social que es una de las finalidades de la educación.

En la inclusión el elemento clave no es la individualización sino la diversificación de la oferta educativa y la personalización de las experiencias comunes de aprendizaje con el fin de logar el mayor grado posible de participación de todos los estudiantes, sin perder de vista las necesidades de cada uno.

Todo lo anterior significa avanzar hacia diseños universales, en los que el currículo y la enseñanza consideren de entrada la diversidad de necesidades de todos los estudiantes, en lugar de planificar pensando en un "alumno promedio" y luego realizar acciones individualizadas para dar respuesta a las necesidades de determinados estudiantes.

La inclusión social educativa propicia la social y el acceso a la justicia social, por lo cual, es indispensable fomentarla en un Estado Social y Democrático de Derecho.

Es necesario cambiar nuestras prácticas docentes y abrir las fronteras de la educación/investigación para adoptar las mejores prácticas inclusivas.

Un ejemplo de ello es el recientemente aprobado plan de estudios de la carrera de abogado en la Universidad de Guadalajara que incluye como ejes transversales la ética, la sustentabilidad, la equidad de género, la cultura de la legalidad, el emprendimiento, los derechos humanos, la internacionalización, la responsabilidad social y la cultura de paz.

Enhorabuena por ese gran esfuerzo institucional.

Otoño 2016

Directora-Editora 


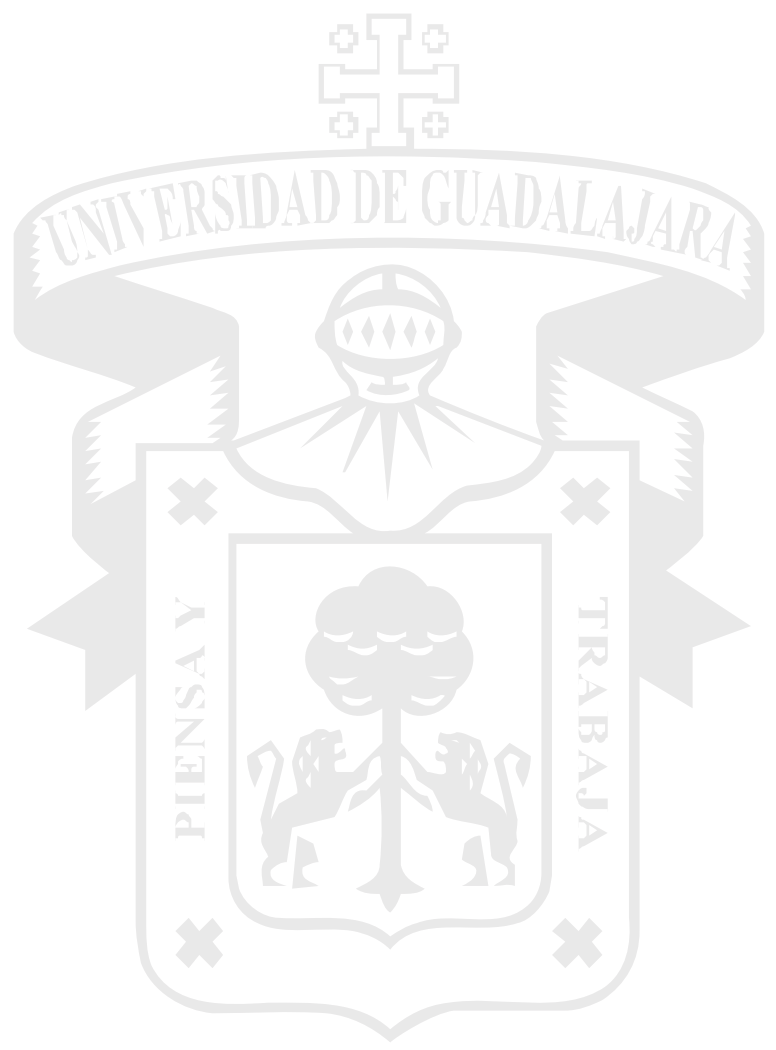

